\title{
Ebola controls at US medical meeting spark protest
}

\section{Researchers say that exclusion of those recently in affected areas could undermine Ebola response.}

\section{Erika Check Hayden}

30 October 2014

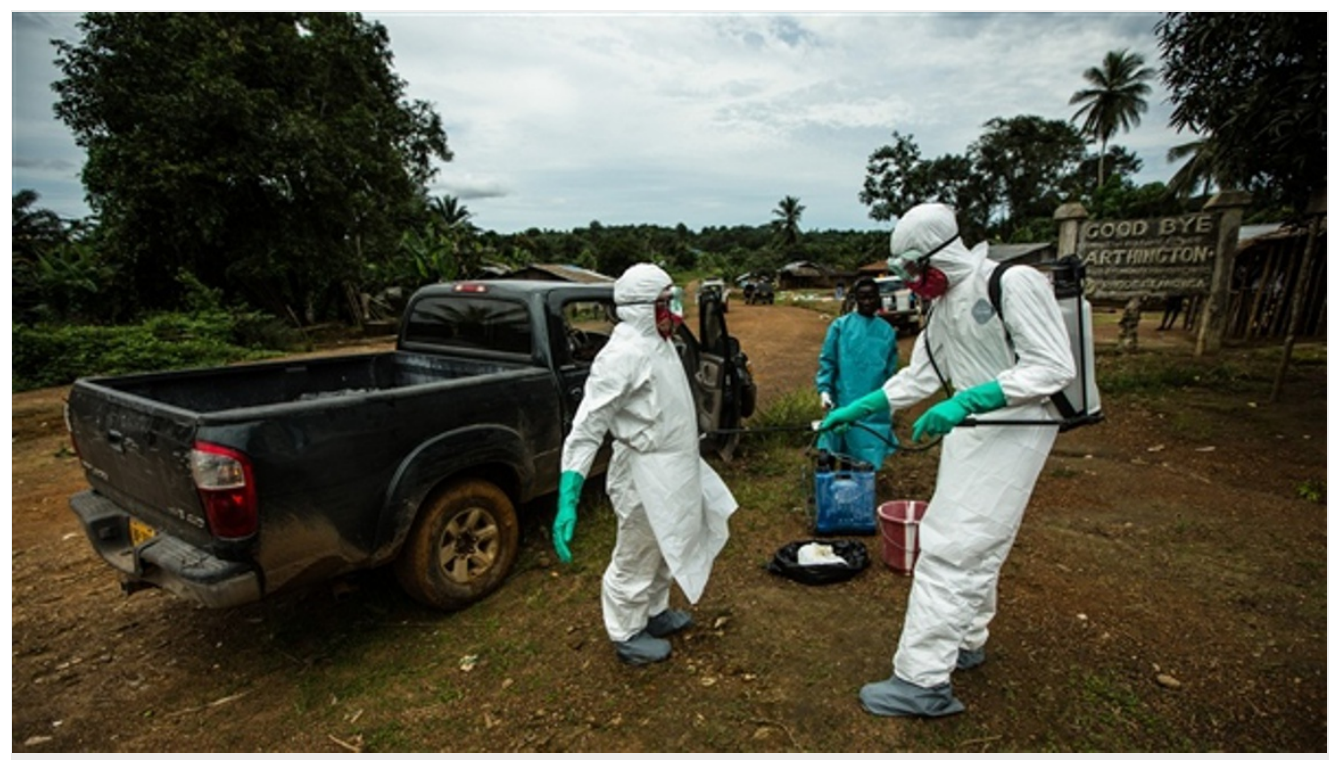

Morgana Wngard/USAID

Health-care workers who have been working in Ebola-affected nations such as Liberia have been asked not to travel to New Orleans, Louisiana, to attend a major medical meeting.

Scientists are protesting against the state of Louisiana's decision to effectively ban people who have recently returned from Ebolaaffected areas from attending a major meeting in New Orleans.

On 29 October, Louisiana officials told organizers of the annual meeting of the American Society of Tropical Medicine and Hygiene that recent returnees from the three West African nations most affected by the Ebola outbreak would be asked not to attend the meeting, which is to be held from 2 to 6 November.

The move could hamper efforts to control the Ebola outbreak, says Christopher Plowe, incoming president of the society and head of malaria research at the University of Maryland School of Medicine in Baltimore.

"This meeting is a place for people who are working on Ebola to share the latest information and go back better prepared to fight the epidemic," Plowe says. "There is a potential hindrance to that effort of people not being able to come to the meeting."

The policy goes beyond guidelines issued on 27 October by the US Centers for Disease Control and Prevention (CDC), which require people to quarantine themselves only if they have symptoms of Ebola virus disease (EVD) or known exposure to the virus

Louisiana, however, has asked that anyone who has been to Ebola-affected countries in West Africa stay away from the meeting.

"We have requested that any individuals that will be traveling to Louisiana following a trip to the West African countries of Guinea, Liberia, and Sierra Leone or have had contact with an EVD-infected individual remain in a self-quarantine for the 21 days following their relevant travel history," wrote Kathy Kleibert, the secretary of the state's department of health and hospitals, and Kevin Davis, director of the Governor's Office of Homeland Security \& Emergency Preparedness, in a letter dated 28 October.

"Given that conference participants with a travel and exposure history for EVD are recommended not to participate in large group settings (such as this conference) or to utilize public transport, we see no utility in you traveling to New Orleans to simply be confined to your room," the letter states. 


\section{Critical response}

The society notified all meeting attendees of the policy in an e-mail on 28 October. Some researchers have already cancelled their trips. Piero Olliaro, head of intervention and implementation research on neglected tropical diseases at the World Health Organization in Geneva, Switzerland, and a visiting professor at the University of Oxford, UK, was scheduled to present research at the meeting on malaria and the parasitic disease schistosomiasis. He returned to Oxford from a trip to Guinea on 22 October, where he was part of a team that was scouting locations for clinical trials of experimental Ebola drugs. He says that he wore protective equipment when visiting treatment centres, has no fever or other symptoms of EVD and, according to CDC guidelines, need not be restricted from public gatherings.

"Public health should be based on evidence, and this policy is clearly not guided by evidence," Olliaro says. "The only effect that this and other similar measures in the United States could have is do discourage people from volunteering and going to aid the response."

Other states have also drawn criticism for overly strict policies. Last week New York and New Jersey announced mandatory quarantines for all health-care workers returning from West Africa. But on Sunday the two states relaxed their rules to allow returned health-care workers to spend 21 days at home, noting that there is no evidence that people without symptoms of the disease can infect others. Louisiana officials seem not to be contesting this fact.

"From a medical perspective, asymptomatic individuals are not at risk of exposing others; however, the State is committed to preventing any unnecessary exposure of Ebola to the general public," Kleibert and Davis wrote.

\section{Travel cancellations}

Médecins Sans Frontières (also known as Doctors Without Borders) confirmed that its tropical-medicines adviser, Estrella Lasry, will no longer attend the meeting because she recently returned from Liberia. Nature also confirmed travel cancellations by other US and UKbased researchers who were not able to speak publicly about the travel ban.

Researchers who are still planning to attend the meeting lamented the decision.

"It is a real shame, as many people that cannot attend are on the front line or were recently and we will not be able to learn from their experiences," says malaria researcher Kristin Banek, who is based at the London School of Hygiene \& Tropical Medicine, UK.

"People need to share their experiences in attempting to control the outbreak and treat patients," says virologist Robert Garry of Tulane University in New Orleans. "This will interfere with that. Repeating the same mistakes over again is not a good formula for success."

Nature | doi:10.1038/nature.2014.16256 